\title{
UFORE Modeli'nin Kent Ekosistemine Hizmet Eden Bileşenlerinin İrdelenmesi
}

\author{
Mahmut TUĞLUER ${ }^{1 *}$, Mert ÇAKIR ${ }^{2}$ \\ ORCID 1: 0000-0002-4357-9599 \\ ORCID 2: 0000-0003-0079-0375 \\ ${ }^{1}$ Süleyman Demirel Üniversitesi, Fen Bilimleri Enstitüsü, Peyzaj Mimarlığı Ana Bilim Dalı, 32260, Isparta, Türkiye. \\ ${ }^{2}$ Süleyman Demirel Üniversitesi, Mimarlık Fakültesi, Peyzaj Mimarlığı Bölümü, 32260, Isparta, Türkiye. \\ *e-mail: mahmutugluer@gmail.com \\ Öz
}

Günümüzde ağaçlandırmalarının planlanması ve yönetimi giderek önem kazanmakta, aynı zamanda ağaçlar insanlara ve kent ekosistemine sağladığı hizmet ve katkıları açısından ön plana çıkmaktadır. UFORE (Urban Forest Effects / Kent Ormanı Etkileri) modeli Amerika Birleşik Devletleri'nde geliştirilen ve kentsel ağaç topluluklarının kente sağladığı işlevsel etkilerini belirlemek ve değerlendirmek için kullanılan uluslararası bir modeldir. Bu model sayesinde günümüzün en önemli konularından olan karbon depolama, hava kirliliği kontrolü, bina enerji kullanımı etkileri gibi kent ağaçlarııı kent ekosistemine sağladığı hizmet ve katkıların daha bilimsel bir şekilde ortaya konulması mümkün olabilecektir. Bu çalışmanın temel amacı, UFORE modelin yapısını, uygulama prensiplerini ve bileşenlerini inceleyerek modelin kent ekosistemine katkılarını ve Türkiye koşullarında kullanılabilirliğini irdelemektir.

Anahtar Kelimeler: Karbon depolama, kent ağaçları, ormanlar, UFORE.

\section{Examination of the Components of UFORE Model Serving the Urban Ecosystem}

\begin{abstract}
Nowadays, planning and management of afforestation is gaining importance. At the same time, trees are important in terms of their services and contributions to people and urban ecosystem. The UFORE model is an international model used to assess urban tree communities and is a model developed in the United States. Thanks to this model, it will be possible to present the services and contributions provided by urban trees to the city ecosystem in a more scientific way such as controlling carbon emission, air pollution control, building energy use effects, which are the most important problems of today. The main purpose of this study is to examine the structure, application principles and components of the UFORE model and to examine its contribution to urban ecosystem and its usability under the conditions of Turkey.
\end{abstract}

Keywords: Carbon storage, urban trees, forests, UFORE.

Atıf: Tuğluer, M., Çakır, M. (2019). UFORE Modeli'nin Kent Ekosistemine Hizmet Eden Bileşenlerinin İrdelenmesi. Mimarlık Bilimleri ve Uygulamaları Dergisi (MBUD), 4 (2), 193-200.

DOI: $\underline{10.30785 / \mathrm{mbud} .586754}$ 


\section{Giriş}

Günümüzde artan nüfusla birlikte insan ve doğa ilişkileri yoğunlaşmış, buna bağıı olarak da çarpık kentleşme, çevre sorunları ve doğal kaynakların tahribatı gibi etmenler ortaya çıkarak yaşam alanlarımız olumsuz yönde etkilenmiştir. Tüm bu olumsuzluklar küresel ısınma ve olası etkilerini artırarak yer kürenin geleceğini tehdit eden önemli etkenlerden olmuştur.

Gül vd. (2009)'ne göre yeryüzündeki karbondioksitin nerdeyse \% 97'si doğal yollar ile yayılmaktadır. Antropojen etki ile oluşan sera gazı salınımı ise yalnızca \% 3 olmasına rağmen bu değerin doğal dengelerin bozulmasında önemli etkiye sahip olduğu uzman görüşlerce kabul edilmektedir. Özellikle son 30 yıl içerisinde insan faaliyetlerinin artması ile birlikte atmosferdeki sera gazı miktarında önemli bir artış gerçekleşmektedir. Bu artışın yer küreyi tehdit etmekte ve doğal dengelerin git gide bozulmasında en önemli etkenlerden biri olduğu kabul edilmektedir.

Küresel ısınma dünyamı üzerinde önemli bir sorun haline gelmiştir. Ancak dünyayı tehdit bu durum, endişelenmeyi gerektirecek kadar yakın bir gelişme olarak algılanmasa da yavaş ve sürekli gelişen bu sorunun gelecekte dünyayı birçok yönden olumsuz etkileyebileceği ve beraberinde insan neslinin bile tehlikeye gireceği belirtilmektedir. (UNFCCC, 2005).

Dünyadaki CO2 (karbondioksit) için depo alanlarının atmosfer, okyanuslar ve karasal biyosferlerdir. Karasal biyosferin önemli bir kısmını ormanlar teşkil etmektedir. Ormanların küresel ısınmanın etkilerinin azaltılması ve iklim değişikliği konusunda önemlidir. Bu nedenle gelişmiş ülkelerde küresel ısınmanın etkilerinin azaltılması ve iklim değişikliği konusundaki en önemli eylemlerden birisi $\mathrm{CO}^{\prime}$ 'in orman ekosistemlerinde tutulmasıdır. Bu eylem genel olarak karbon depolama olarak adlandırılmaktadır. Özellikle kentsel alanlarda $\mathrm{CO} 2$ salınımını azaltmak ve karbon depolama için kent ağaçları ve kent ormanlarının rolü oldukça önemlidir. (Gül, vd., 2009). Kentlerde yaşam kalitesini artırmak, kenti işlevsel ve estetik açıdan iyileştirmek, karbon tutmak ve $\mathrm{CO}_{2}{ }^{\prime} i$ azaltmak amacıyla kent ağaçlarının varlığı önem arz etmektedir.

Tuğluer (2015)'e göre peyzaj mimarlığı ve ilgili meslek disiplinleri açısından önemlilik arz eden kentsel açık ve yeşil alanların, karbon tutma ve depolama gibi kent ekosisteminin iyileştirilmesinde önemli bir rolü bulunmaktadır. Bu amaçla yapılacak çalışmalarda yeşil alanların, kent ekosistemine sağlayacağı katkıların bilimsel çalışmalarla belirlenmesi intiyaç haline gelmiştir. Bu bağlamda kent ağaçlarının strüktürel özelliklerini ve işlevsel etkilerini belirlemek amacıyla Amerika Birleşik Devletleri'nde UFORE adlı yazılım geliştirilmiştir. Bu etkileri hesaplayabilmek ve kontrol etmek için kent ağaçları hakkında envanter verilerinin toplanması gerekmektedir. UFORE modeli de her ağacın envanter verilerinden yararlanarak biyokütle ve karbon depolama tahminleri, hava kirliliğini kaldırma, uçucu organik bileşen emisyonları ve bina enerji kullanımına etkilerini gibi verileri hesaplamayı sağlayan bir yazılımdır.

Bu çalışmanın amacı, UFORE modelin yapısını, uygulama prensiplerini ve bileşenlerini inceleyerek modelin kent ekosistemine katkılarını ve ülkemiz koşullarında kullanılabilirliğini irdelemektir.

\subsection{UFORE Modeli}

UFORE modeli kent ağaçlarını değerlendirmek için kullanılan uluslararası bir modeldir. Bu model Amerika Birleşik Devletleri'nde geliştirilmiştir. Dünya üzerinde yaklaşık 50 şehirde uygulanmıştır. UFORE modeli kent ağaçlar ile ilgili verileri bir sistem üzerine kayıt edilmesiyle her bir tür için bilgi edinilmesini amaçlar. Sistem üzerine entegre edilecek veriler bölgeye ait kurumlar ile işbirliği içerisinde belirlenerek veriler bir standart haline getirilmiştir (USDA Forest Service, 2014).

\subsubsection{Modelin hesapladığı parametreler}

Model, ağaç tür dağılımı, ağaç taç örtüsü, yoğunluğu, sağlığı, yaprak alanı, yaprak biyokütlesi, çalı ve toprak örtüsü gibi kent orman yapısı hakkındaki bilgileri aşağıdaki bazı formüller vasıtası ile hesaplamaktadır.

$\mathrm{CF}=\mathrm{GA} / \mathrm{TA}$

CF: taç rekabet faktörü

GA: ağacın taç alanı

TA: ağaç tacının yüzde değeridir. 
$\mathrm{K}=(\% \mathrm{CON} \times 0.52)+(\% \mathrm{HRD} \times 0.65)$

$\%$ CON: alandaki ibreli taç yüzdesi

\% HRD geniş yapraklı ağaçların taç yüzdesi

Ayrıca ışık tükenme katsayısı ibreli ağaç türleri için 0,52; yaprağını dökenler için ise 0,65'tir.

La I $=\ln \left(\mathrm{I} / \mathrm{I}_{\mathrm{o}}\right) \mathrm{I-k}$

La I: yaprak yüzeyi indeksi

L: taç altındaki ışık yoğunluğu

Io: tacın maruz kaldığı ışık yüzdesi

k: ışık tükenme katsayısıdır (USDA Forest Service, 2014).

\subsubsection{UFORE Modeli'nin kullanım amacı}

UFORE Modeli aşağıdaki parametreli hesaplamak amacıyla kullanılmaktadır (USDA Forest Service, 2014). Bu parametreler;

- Kent ormanının saatlik uçucu organik bileşik miktarının tahmini,

- Hava kirliliğinin saatlik verileri,

- Ağaçların hava kalitesi üzerindeki etkileri,

- Kent ağaçlarının karbon tutma kapasiteleri,

- Ağaç türlerine göre hastalık ve böcek potansiyeli,

- Polen alerjisi değerlendirmesi,

- Egzotik türlerin kompozisyonu,

- Ağaç terleme oranları tahminleridir (USDA Forest Service, 2014).

\subsubsection{UFORE Modeli'ni oluşturan modüller}

Kent ormanı yapısı: Bu kısım kent ormanının yapısının daha iyi anlaşılması, uygulanması ve kullanılması için orman yapısının sistem içerisine kayıt edildiği aşamadır. Sisteme kayıt edilen bilgiler arasında ağaç tür kompozisyonu, ağaç yoğunluğu, ağaç sağlığı, yaprak yüzey alanı, yaprak biyokütlesi ve ağaç biyokütlesi tahminleri gibi verilere intiyaç duyulmaktadır.

Örnekleme: Bu aşamada kent ormanının yapısını belirlemek amacıyla iki örnekleme metodu kullanılmaktadır:

- Randomize Izgara örnekleme yöntemi: Bu yöntemde, çalışma bölgesi eşit parçalara bölünür. İstenilen sayıya göre ızgara gridleri elde edilir. Bu alan istenirse daha küçük gridlere ayrılabilir. Rastgele örnekleme yaklaşımı değerlendirme aşamasının daha kolay biçimde olmasını sağlamaktadır. Bu örnekleme metodu vasıtası ile geleceğe dönük nüfus artış miktarı ve maliyet hesaplamaları ile ilgili değişimlerin tahminleri elde edilecektir.

- Tesadüfi örnekleme yöntemi: Bu örnekleme metodunda, öncelikle çalışma alanı rastgele dağıtılır ve tabakalara bölünür. Bu işlem arazide çalışan kullanıcıları dağıtarak tabakalara ayırmayı sağlar.

Veri toplama ve değişkenler: Bir UFORE modeli uygulama arazisi üzerinde toplanan verilerin dört genel türü vardır:

- Genel plan bilgileri: Arazinin genel özelliklerini tanımlamak için kullanılır.

- Ağaç bilgileri: Ağaçların bazı yapısal özelliklerini tahmin etmek, karbon depolama ve tutma kapasiteleri, enerji tasarrufu etkileri, VOC emisyonları, ağaçların miktarı ve olası zararlı etkileri vb. bilgileri içermektedir.

- Çalı bilgileri: Çalıların yaprak alanı, biyokütle tahmini, kirlilik tahmini uçucu organik maddelerin çalılar tarafından salınımı tahminleri gibi bilgileri içerir.

- Toprak üstü verileri: Çalışma alanındaki değişken toprak örtüsü çeşitlerinin dağııımını içerir.

Değişken açıklama: Kullanılacak örnekleme çeşidine göre rastgele ya da tabakalı olma durumu belirlenerek arazilerin tespit edilmesi gerekmektedir. Arazi sayısı arttıkça modelin hesaplayacağı parametrelerdeki hatalar azalacaktır. 
Referans verileri: Alandaki bölümleri ve parselleri tanımlamak amacıyla arazi ölçüm verileri ve konumun saptanması için iki adet referans noktasının belirlenmesine ihtiyaç duyulmaktadır. Her referans noktası için birimlerin uzaklığı, yönü, açısı vb. bilgiler elde edilmelidir. Referans noktası yapısal bir öğenin üzerine gelirse ölçüm noktası ağaca göre olmalıdır.

\subsubsection{UFORE Modeli'nin veri tabanı yapısı}

UFORE Modelinin kullanımı için çeşitli veri girişlerinin yapılması gerekmektedir. UFORE modelinin ver tabanı yapısı şu şekildedir;

- Kullanıcılar tarafından girilen arazi verilerini içermektedir.

- Ver tabanı ağaç türleri listesini içermektedir.

- Konumsal ve coğrafi bilgileri içermektedir.

- Hava kalitesi ile ilgili parametreler yersel ölçüm merkezlerinden elde edilmelidir.

- Kirlilik ile ilgili veriler Amerika Birleşik Devletleri (ABD) Çevre Koruma Ajansı'nın sitesinden elde edilir.

\subsubsection{UFORE Modeli'nin uluslararası sürümü}

UFORE modelini $A B D$ haricindeki ülkelerde kullanabilmek için uluslararası versiyon olan i-Tree programının Eco programı geliştirilmiştir. Bu program uluslararası bir proje geliştirmek için bazı verilere ihtiyaç duyulmaktadır. Bu veriler;

Konum bilgisi: UFORE Modeli çalıştırmak için bölgesel analizlerin yapılması gereklidir. Çalışmayı gerçekleştiren kullanııılar konum bilgilerini sisteme girmesi gerekmektedir.

Yeni tür bilgisi: Veri tabanında bulunmayan bir ağaç türü ile karşıllaşılması halinde, kullanıcılar yeni tür verisi girebilmek için gerekli bilgileri içeren ve sisteme entegre halde bulunan bir form doldurmaları gerekmektedir. Yeni tür sisteme entegre edildiğinde sistemde bulunmayan tür ile ilgili hesaplama yapılabilecektir.

Saatlik kirlilik verileri: Bu veri kirlilik tahminleri için ihtiyaç duyulmaktadır. Kullanıcılar saatlik kirlilik verilerini yerel merkezlerden elde ederek standart forma göre oluşturmalıdır.

Saatlik iklim verileri: Bu veri uluslararası olarak standart bir formatta oluşturulmamıştır. Kullanıcı verileri belirlemek için bölgedeki meteoroloji istasyonundan hava veri tabanı haritasını elde edilerek sisteme uygun şekilde kayıt etmelidir. Bu veriler kirliliği giderme ve biyojenik emisyon tahminleri için gerekmektedir.

Sınır tabaka yüksekliği verileri: Kirlilik giderme tahminler için gerekli olan bir veridir. Sınır tabaka yüksekliği bilgileri yersel çapta mevcut ise kullanıcı bu verileri sisteme göre biçimlendirmelidir.

Yerel türler için gölgelendirme katsayıları: Türlerin ışı̆ı̆ örtme yüzdeleri ekosistem tahminlerinin gelişmesine katkı sağlamaktadır. Bu nedenle bu veriye ihtiyaç duyulabilmektedir.

Biyokütle formülleri: Ağaçların tepe çaplarıyla orantılı olarak taç örtüsünün karbon depolama tahminlerinin geliştirilmesine yardımcı olacaktır.

Büyüme oranları: Türlerin yıllık ortalama büyüme katsayılarını tahmin etmek için kullanılacak verdir.

Yerel türler: Sistem üzerindeki türler Amerika Birleşik Devletleri'ndeki mevcut türlerden oluşmaktadır. Uluslararası kullanıcıların sistemden faydalanmaları için kendi yerel türlerini sisteme entegre etmeleri gerekmektedir.

\subsubsection{Uluslararası değişkenler}

Uluslararası formatta bazı kullanımlar farklılık gösterebilmektedir. Verileri girilirken ondalık olarak sistemlerde virgül kullanılmalıdır. ABD dışı ülkelerde 6,543.21 ile 6.543,21 gösterimi farklıdır. Bu farklar modelin çalışmasında sorunlara yol açabilecektir. Uluslararası tür farklılıklarını gidermek için, ortak veri tabanında gerekli olan bu türler hakkında bilgi ile birlikte, türler listesi veri tabanında bulunmayan, kendi ülkesinde bulunması muhtemel türler listesi vermek gerekecektir. Bunun için aşağıdaki verilere intiyaç duyulmaktadır. 
- Ağaçların gölgelendirme katsayıları belirlenmelidir

- Yaprak tipleri, yaprağını döken, her dem yeşil, otsu ve bilinmeyen olarak belirlenen verilerdir.

- Yaprağın palmiye, köknar, sedir veya otsu gibi hangi türe sahip olduğunun belirlenmesi gerekmektedir.

- Türlerin bulunduğu ülke hangi kıtada olduğu belirtilerek konum verisi sisteme girilmelidir.

- Ülkelerin yerel türler belirlenmelidir.

- Modelde ülkesel zararlıların belirlenmesi gereklidir.

- Ortalama ağaç yükseklikleri belirlenmelidir.

- Ağaçların tür, cins, sınıf ve altsınıf bilgileri gereklidir (Nowak ve Crane, 1998).

\subsection{UFORE Modeli'nin çıktıları}

UFORE Modeli uygulama esasları ve çalışma prensipleri ele alınarak uygulandığı takdirde kent ağaçlarının kent ekosistemi etkileri üzerine yapısal ve işlevsel olarak aşağıdaki çıktıları vermektedir;

\subsubsection{Yapısal çıktılar}

Ağaç tür kompozisyonu (\%): Çalışma alanlarında kaydedilen ağaç türleri toplam ağaç türleri içindeki \% katılım değerleri,

Ağaç sayısı (adet ve \%): Çalışma alanındaki her bir ağaç türünün toplam sayısı ve yüzdesi,

Ağaç gövde göğüs çapı dağılımı (\%):Her bir ağaç türünün sahip olduğu gövde göğüs çaplarının yüzde dağılımı,

Ağaç yoğunluğu: Çalışma alanındaki ağaç yüzeyi toplam alanı $\left(\mathrm{m}^{2}\right)$,

Ağaç sağı̆̆̆ı (\%): Çalışma alanlarındaki ağaçların sağııkı ve sağlıklı olmama durumu yüzdeleri,

Ağaç yaprak yüzeyi $\left(\mathbf{m}^{2}\right)$ : Yaprak yüzey alanı ve alanda kapladığı yaprak yüzey alanı yüzdesi,

Yaprak biyokütlesi: Regresyon denklemleri ve gölgeleme katsayıları vasıtasıyla ağaçların yaprak biyokütlesinin hesaplanması.

\subsection{2. İşlevsel çıktılar}

Karbon tutma ve depolama: Ağaçların yıllık karbon depolama ve tutma tahminleri ve yıllık büyüme mevsim uzunluğu, rekabet ve ağaç koşulları üzerinde kurulan yıllık büyüme oranları tahmin edilmesi,

Hava kirliliğini kaldırma: İklim verileri, kirlilik konsantrasyon verileri, alan faktörleri ve yaprak yüzeyi üzerine kurulan saatlik kirlilik kaldırma değerlerinin tahmin edilmesi,

Biyojenik uçucu organik bileşimi (VOC) emisyonu: Alan faktörleri, iklim verileri, yaprak biyokütle oranlarına bağlı olarak yıllık emisyonun tahmin edilmesi,

Bina enerji kullanım etkileri: Oturulmaya elverişli yapıların bina enerji kullanımı üzerinde ağaç etkilerinin belirlenmesi,

Strüktürel maddi değeri: Karbon emisyonu miktarı, hava kirliliği ve bina enerji kullanımının maddi değerinin tahmin edilmesi.

\subsubsection{Karbon tutma ve depolama}

Atmosferik $\mathrm{CO}_{2}$ ve diğer sera gazlarının (metan, kloroflorokarbonlar, azot oksit) atmosferdeki sıcaklık seviyesinin artışına neden olduğu bilinmektedir. Yaşam süreçleri boyunca ağaçlar, atmosferdeki $\mathrm{CO}_{2}{ }^{\prime} \mathrm{i}$ temizler ve $C$ kütlelerini biyokütle içinde depolar. UFORE modeli kent ağaçlarının allometrik denklemlerle biyokütlesi ve büyüme katsayılarını da baz alarak karbon depolama miktarını tahmin etmektedir. Karbon depolama miktarları tahmin edilirken biyokütle miktarı, büyüme katsayıları, yaprak tipi gibi veriler kullanılmaktadır. Model içerisinde denklemlerle hesaplanarak elde edilen türlere ait katsayılar bulunmaktadır. Model, herhangi bir türe ait veri içermediği zaman en yakın türe ait katsayıyı kullanmaktadır. 


\subsubsection{Hava kirliliğini kaldırma}

UFORE hava kirliliğinin ağaçlar ve çalılar üzerindeki kuru birikimini tahmin etmek için kullanılmaktadır. Model saatlik meteorolojik verileri kullanılarak ağaç kaplı alanlarda O3, SO2, NO2, CO ve PM10'un yıl boyunca ağaçta birikimlerinin tahminleri yapmaktadır. Meteorolojik veriler bölgesel meteoroloji istasyonlarından elde edilmektedir. Ayrıca model kirlilik verilerini hesaplayabilmek için yaprak yüzey alan miktarına ihtiyaç duymaktadır. Yaprağını döken ağaçlar için yapraklı dönemler baz alınmaktadır. Bu sayede ağaçların havadaki zararlı partiküllerin ne kadar miktarda yaprak yüzeyinde biriktiğini tahmin edebilmektedir.

\subsubsection{Biyojenik uçucu organik bileşimi (VOC) emisyonu}

Uçucu organik bileşikler (UOB), atmosferik fotokimyasal reaksiyonlara katılan karbon monoksit, karbondioksit, karbonik asit, metalik karbürler veya karbonatlar ve amonyum karbonat hariç olmak üzere, US EPA (Birleşik Devletler Çevre Koruma Ajansı) tarafından ihmal edilebilir fotokimyasal reaktifliğe sahip olduğu belirtilen herhangi bir karbon bileşiği anlamına gelir. Sayısal olarak verilen tanımda uçucu organik bileşiklerin $25^{\circ} \mathrm{C}^{\prime}$ de 10 Pascal $(\mathrm{Pa})$ buhar basıncından daha yüksek buhar basıncında 15 veya daha az karbon atomuna sahip organik bileşikler olduğu belirtilmektedir. Uçucu organik bileşiklerin farklı kaynakları bulunmaktadır. Dünya genelinde uçucu organik bileşik emisyonlarının 1347 milyon ton/yıl biyojenik kaynaklardan, 462 milyon ton/yıl da antropojenik kaynaklardan kaynaklandığı tahmin edilmektedir. Atmosferik Uçucu organik bileşiklerin antropojenik kaynakları; ulaşım için fosil yakıtların kullanımı, tüketim mallarının üretimi ve çeşitli endüstriyel proseslerdir. Uçucu organik bileşiklerin doğal kaynakları ise; ağaçlar, bitkiler, vahşi hayvanlar, doğal orman yangınları ve bataklıklardaki anaerobik süreçlerdir.

Bu model kent ağaçlarının biyojenik uçucu organik bileşimi emisyonunun miktarını tahmin etmektedir. Uçucu organik bileşim (VOC) emisyonlarının miktarı ağaç türlerine, yaprak biyokütlesine, hava sıcaklığına ve diğer çevresel faktörlere bağlıdır.

Model bu verileri kullanarak ağaçlara ait emisyon miktarını tahmin etmektedir. Örneğin, izopren, monoterpenler için VOC emisyonu (E) aşağıdaki formüle göre tahmin edilmektedir

(TgC ağacı-1 saat-1 sıcaklıkta T (K) ve PAR akısı L ( $\mu$ mol m-2 s-1)) $E=B E \times B \times \gamma(12)$

Burada BE 30 oC'de $\mu \mathrm{gC}$ (g yaprak kuru ağırlığı) -1 hr-1 ve 1,000 $\mu \mathrm{mol}$ m-2 s-1'in PAR akışında baz cinsi emisyon oranıdır. B türü yaprak kuru ağırlığı biyokütlesidir (g).

$\gamma=[\alpha \cdot \mathrm{cL} 1 \mathrm{~L} /(1+\alpha 1 \cdot \mathrm{L} 2) 2] \cdot[\exp [\mathrm{cT} 1(\mathrm{~T}-\mathrm{TS}) / \mathrm{R} \cdot \mathrm{TS} \cdot \mathrm{T}] /(0.961+\exp [\mathrm{cT} 2(\mathrm{~T}-\mathrm{TM}) / \mathrm{R} \cdot \mathrm{TS} \cdot \mathrm{T}])]$

L'nin PAR akışı olduğu izopren için; $a=0.0027$; $\mathrm{CL1}=1.066$; $\mathrm{R}$ ideal gaz sabiti $(8.314 \mathrm{~K}-1 \mathrm{~mol}-1), \mathrm{T}(\mathrm{K})$ hava sıcaklığı olduğu kabul edilen yaprak sıcaklığıdır, TS standart sıcaklıktır (303 K) ve TM $=314 \mathrm{~K}, \mathrm{CT} 1$ $=95.000 \mathrm{~J}$ 'dir. mol-1 ve CT2 = 230,000 J mol-1 olarak verilmiştir.

\subsubsection{Bina enerji kullanım etkileri}

UFORE modeli, ağaçların enerji kullanımını ve bunun sonucunda binalardan kaynaklanan karbon emisyonları üzerindeki etkilerini tahmin etmektedir. Model tahmin yapabilmek için ağaç büyüklüğü, binaya uzaklığı, bina tipi, bina yönü, iklim bölgesi, yaprak türü ve alan üzerindeki ağaç örtüsü, ağaç gölgeleme faktörü, rüzgâr kırıcı etkileri gibi verilere ihtiyaç duymaktadır. Bu sayede binaların etkisiyle salınan karbon miktarının ne kadarının ağaçlar tarafından tutulduğu tahmin edilebilmektedir. Bina enerji kullanımlarının bu modelde hesaplanabilmesi için ayrıca yerel bazda binaların enerji kullanım miktarlarının belirlenmiş olması gerekmektedir.

\subsubsection{Strüktürel maddi değeri}

Bir ağacın strüktürel değeri o ağacın bulunduğu konuma ve ortam şartlarına göre ortamın tüketim miktarına karşılık gelen yıllık olarak ortalama telafi ettiği maddi değerini belirtmektedir. i-Tree Eco programı bu değerleri ABD koşullarına göre tahmin etmektedir. Bu nedenle uluslararası koşullarda Amerika'nın değer tahmin sistemine dayanmaktadır. Modelde strüktürel ağaç değeri ağacın depoladığı karbon miktarının son yıllardaki verilere göre karbonun ton başına parasal değeriyle ilişkilendirilmesiyle hesaplanmaktadır. Bu değer yıllık 23\$/Ton C olarak belirlenmiştir. 


\subsection{UFORE Modeli'nin kullanımındaki bazı kısıtlamalar}

ABD'de geliştirilen UFORE modeli kapsamında uluslararası şehirler için oluşturulan i-Tree Eco versiyonun kullanımında Çalışma yapılacak ülkelerde yerel bazı verilerin temin edilmemesi veya iyileştirmeler olmadan bu modelin iyi sonuç vermemektedir. Çünkü bu model yerel ve uluslararası boyutta verilere dayalı tahminler üretebilmektedir. Bina enerji kullanım etkileri bina enerji miktarları tespit edilmemiş bölgeler için uygulanamamaktadır.

Model hava kirliliği verileri ve biyojenik uçucu organik bileşimi tahminlerini gerçekleştirebilmesi için $\mathrm{SO}_{2}, \mathrm{PM}_{10}, \mathrm{CO}, \mathrm{NO}, \mathrm{NO}_{2}, \mathrm{O}_{3}$ gibi bileşenleri günlük olarak çalışma süresi boyunca istemektedir. $\mathrm{Bu}$ bileşenlerin tamamının veya bir kısmının bulunmadığı bölgeler için bu model hesaplama yapamamaktadır.

I-tree programı ücretsiz olarak kullanılmasına rağmen analiz sürecinin ABD'deki merkez tarafından yapılması nedeniyle analiz süreci uzun sürmekte kullanıcılar bireysel olarak sonuçlara ulaşamamaktadır. Bu durum en önemli dezavantaj olarak kabul edilebilmektedir. Dünyada UFORE modelinin kullanıldığı bazı bölgeler Şekil 1'de verilmiştir. Ayrıca ülkemizde de i-Tree Eco kullanılarak Tuğluer (2015) tarafından Isparta ve Selim ve Atabey (2019) tarafından Antalya kentinde çalışmalar yapılmışır.

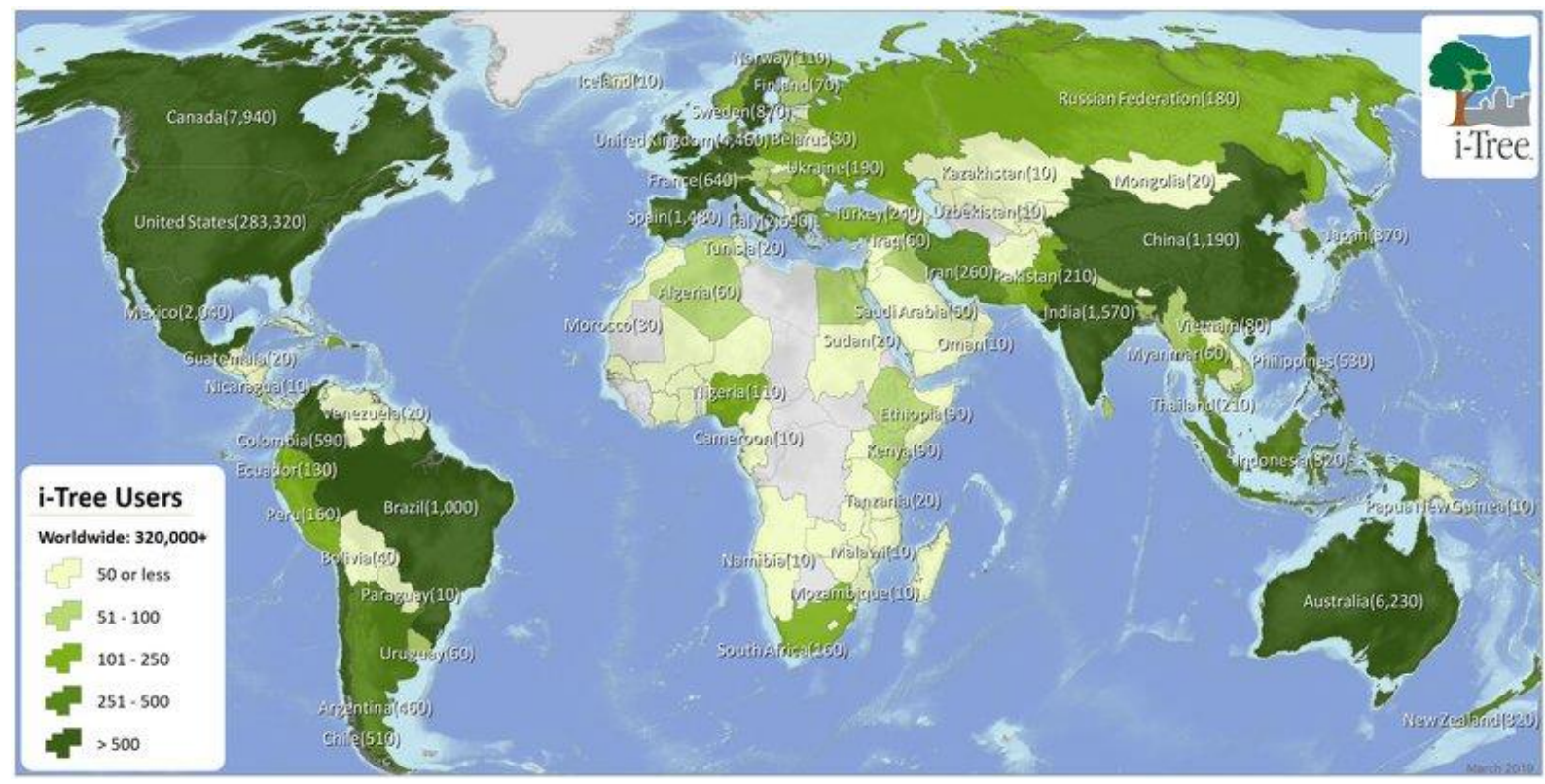

Şekil 1. UFORE modelinin uygulandığı bazı bölgeler (URL 1.)

\section{Sonuç ve Öneriler}

UFORE modeli kent ağaçları ve kent ormanlarının yapısal özelliklerini ve çevreye sağladığı işlevsel özelliklerini belirlemek ve tahminlerde bulunmak amacıyla Amerika'da geliştirilen bilgisayar yazılımlı bir araçtır.

Bu modelin sağlıklı bir şekilde kullanılabilmesi için yapılması gerekenler şu şekilde özetlenebilir; i-Tree Eco versiyonu bileşenlerinin hesaplanması için çalışma alanına yönelik detaylı bir şekilde ağaç envanterinin ve çevresel verilerinin elde edilmesini gerektirmektedir. UFORE Modelinin Türkiye koşullarında uygulanabilmesi için ağaç türlerine ait envanter çalışmaları için UFORE modeline uygun standartlarda bir form oluşturulmalıdır. Her ağaç için yaprak çeşidi, gövde genişliği, ağaç taç yüzdesi, ağaç tacı çap genişliği, ağaç sağlığı verileri vb. veriler elde edilerek bir envanter havuzu oluşturulmalıdır. Bu sayede modelin kolaylıkla envanteri çıkarılan bölgelerde uygulanması söz konusu olabilecektir

Çalışma yapılacak alanda bina enerji kullanım etkileri belirlenmesi gerekmektedir. Hava kirliliği kaldırma ve biyojenik ucuçu organik emisyon tahminleri için bölgesel meteorolojik verilerin günlük ve eksiksiz olması gerekmektedir. 
Sonuç olarak kent ağaçlarının işlevsel etkileri konusunda yerel kurumlar ve kullanıcılar tarafından UFORE metodunun yaygınlaştırıması gerekmektedir. İlerleyen zamanlarda Türkiye koşullarına özgü katsayıların oluşturulması önem arz etmektedir. Ülke çapında envanter havuzu oluşturulması ve sürdürülebilirliğinin sağlanması gerekmektedir. Konuyla ilgili gerekli ilgi ve destek sağlanmasıyla bu metodun Türkiye şartlarına göre geliştirilmesi mümkün olabilecektir.

Kentlerin yaşanabilir mekânlar haline getirilmesi için, kent ağaçlarının ve ormanlarının rolü büyüktür. Ağaçların karbon salınımının azaltılmasında ve küresel ısınma ile mücadelede, önemli bir varılı olduğunun farkına varılması, bilimsel ve teknik boyutta çalışmaların eyleme dönüştürülmesi ile mümkün olabilecektir.

Bu çalışmada Amerika Birleşik Devletleri'nde Nowak ve Crane (1998) tarafından geliştirilen UFORE Modeli'nin kullanım kılavuzundan ve Nowak vd. (2008)'nin yapmış oldukları çalışmadan yararlanılmıştır.

\section{Kaynaklar}

Gül, A., Topay, M., Özaltın, O. (2009). Küresel Isınma Tehdidine Karşı Kent Ormanlarının Önemi. Uluslararası Davraz Kongresi, 24-27 Eylül 2009, Isparta, 221-234.

Gül, A., Çatal, Y., Çoban, H.O., Polat, E., Gülcü, S., Yılmaztürk, A., Topay, M. (2015). Kent Ağaçları Bilgi Sistem Modeli. TUBITAK 110Y301. Nolu Proje Sonuç Raporu 15/11/2011-03/01/2015 (Basılmamış).

Nowak, D. J., Crane, D. E.,Stevens J. C., Hoehn, R. E., Walton, J. T., Bond, J., (2008). A Ground-Based Method of Assessing Urban Forest Structure and Ecosystem Services. Arboriculture \& Urban Forestry, 34(6), 347-358.

Nowak D. J., Crane. E. (1998). The Urban Forest Effects (UFORE) Model: Quantifying Urban Forest Structure and Functions, Integrated Tools Proceeding, Idahio USA.

Nowak, D.J. (1996). Estimation Leaf Area and Leaf Biomass of Open-Grown Deciduous Urban Trees. Forest Science, 42(4), 504-507.

Nowak, D.J., Crane, D.E. (2002). Carbon Storage and Sequestration by Urban Trees in the USA. Enviromental Pollition, 116, 381-389.

Selin, C., Atabey, S. (2019). Determination of the Benefits of Urban Road Plantings: A Case Study of Atatürk Boulvard (Antalya). 1. International Ornamental Plants Congress Book of Abstracts, 9-11 October 2019, p.140, Bursa, TURKEY.

Tuğluer, M. (2015). Kent Ağaçlarının Çevresel Etkileri ve Değerinin Belirlenmesinde UFORE Modelinin Kullanımı ve Isparta Örneğinde İrdelenmesi. Süleyman Demirel Üniversitesi, Fen Bilimleri Enstitüsü, Yüksek Lisans Tezi, 110s, Isparta.

UNFCCC (United Nations Framework Convention on Climate Change). (2005). Kyoto protocol status of ratification. United Nations Framework Convention on Climate Change.

URL-1. (2019). I-Tree International. Erişim Tarihi: 05.05.2019 https://www.itreetools.org/support/resourcesoverview/i-tree-international. 